\title{
PERFIL DOS ESTUDANTES DOS DOIS PRIMEIROS ANOS DO CURSO DE MEDICINA DE UMA INSTITUIÇÃO PRIVADA DE ENSINO DE MINAS GERAIS
}

Vitor Carvalho Alvarenga, Jorge Luiz Coelho de Sousa, Isabella Campos Rodrigues, Virgínia Maria Motta de Carvalho, Lorena Souza e Silva. Perfil dos estudantes dos dois primeiros anos do Curso de Medicina de uma Instituição privada de ensino de Minas Gerais. Revista Saúde Dinâmica, vol. 1, núm. 1, 2019. Faculdade Dinâmica do Vale do Piranga.

\section{SAÚDE DINÂMICA - Revista Científica Eletrônica FACULDADE DINÂMICA DO VALE DO PIRANGA}

1a Edição 2019 | Ano I- no 1 | ISSN-2675-133X

DOI: 10.4322/2675-133X.2022.001 


\section{Perfil dos estudantes dos dois primeiros anos do Curso de Medicina de uma Instituição privada de ensino de Minas Gerais}

\section{Profile of the students of the first two years of the Medicine Course of a private educational institution of Minas Gerais}

Vitor Carvalho Alvarenga ${ }^{l}$, Jorge Luiz Coelho de Sousa ${ }^{l}$, Isabella Campos Rodrigues ${ }^{l}$, Virgínia Maria Motta de Carvalho ${ }^{1}$, Lorena Souza e Silva ${ }^{1 *}$

${ }^{1}$ Curso de Medicina, Faculdade Dinâmica do Vale do Piranga, Rua G, 205 - Bairro Paraíso -

Ponte Nova-MG - Cep: 35430-302,*lorenanupeb@gmail.com

\section{Resumo}

O presente estudo objetivou traçar o perfil socioeconômico, acadêmico e psicossocial de estudantes dos dois primeiros anos do curso de Medicina de uma instituição privada de ensino localizada na Zona da Mata mineira. A coleta de dados foi realizada mediante aplicação de questionário que abordou questões sobre dados socioeconômicos e acadêmicos dos discentes, qualidade de vida e lazer, percepções sobre o curso e pretensões profissionais. Como principais resultados, foi observado um predomínio de estudantes do sexo feminino $(64,77 \%)$, de etnia branca $(61,79 \%)$, solteiros $(96,51 \%)$, sem filhos (98,79\%), naturais de Minas Gerais (78,66\%), que moram com amigos $(58,13 \%)$, com renda mensal familiar superior à sete salários mínimos (62,35\%). A maioria dos discentes investigados consideram a carga de atividades acadêmicas excessiva $(75,55 \%)$, relatam a ansiedade como o principal fator de interferência no desempenho acadêmico $(81,11 \%)$, possuem menos que quatro horas diárias de lazer $(78,88 \%)$, nunca se submeteram a atendimento psicológico ou psiquiátrico $(53,48 \%)$ e procuraram por apoio psicopedagógico por apenas uma vez durante o curso $(63,63 \%)$. A possibilidade de realização profissional foi a principal motivação apontada como escolha pela Medicina $(62,22 \%)$, a maioria acredita que vai se realizar profissional e financeiramente $(77,27 \%)$ e têm pretensão de fazer residência médica $(62,22 \%)$. Em suma, o estudo mostrou perfil socioeconômico relativamente elevado entre os estudantes avaliados e que o excesso de atividades curriculares causa efeitos prejudiciais sobre suas atividades de lazer. Ademais, estes discentes em sua maioria não procuram redes de apoio psicológico, têm boas perspectivas profissionais e preferência pela residência médica pós formatura.

Palavras-chave: perfil, estudantes, medicina 


\begin{abstract}
The present study aimed to outline the socioeconomic, academic and psychosocial profile of the students of the first two years of the Medicine course of a private teaching institution located in the Zona da Mata, Minas Gerais. Data collection was performed through questionnaire, which addressed questions about socioeconomic and academic data of students, quality of life and leisure, perceptions about the course and professional pretensions. As a main result, a predominance of female students $(64.77 \%)$, white $(61.79 \%)$, single $(96.51 \%)$, without children $(98.79 \%)$, were natural of Minas Gerais $(78.66 \%)$, who live with friends $(58.13 \%)$, with monthly family income higher than seven minimum wages $(62.35 \%)$ and have medical relatives $(56.17 \%)$. The majority of the students investigated considered the load of academic activities excessive $(75.55 \%)$, reported anxiety as the main interference factor in academic performance $(81.11 \%)$, had less than four hours of leisure time per day $(78.88 \%)$, never submitted to psychological or psychiatric care $(53.48 \%)$ and sought psychopedagogical support only once during the course $(63.63 \%)$. The possibility of professional achievement was the main motivation pointed out as a choice for Medicine $(62.22 \%)$, most of the students said they believe that they will do it professionally and financially $(77.27 \%)$ and have the intention to become a medical resident $(62.22 \%)$. In summary, the study showed a relatively high socioeconomic profile among the evaluated students and that the excess of curricular activities causes detrimental effects on their leisure activities. In addition, these students mostly do not seek psychological support networks, have good professional perspectives and preference for post-graduation medical residency.
\end{abstract}

Keywords: profile, students, medicine. 


\section{INTRODUÇÃO}

A graduação em Medicina é uma das mais requisitadas pelos estudantes de Ensino Médio e cursos pré-vestibulares. A escolha pela profissão médica por parte dos acadêmicos vincula-se a motivações conscientes e inconscientes, que agregam a possibilidade de ascensão social, a sensação de tornar-se útil, aliviar os que sofrem, salvar vidas, ter aptidão e vocação pelas ciências biológicas, entre outros (IGNARRA, 2002). No Brasil, seguindo as Diretrizes Curriculares Nacionais (DCNs) do ano de 2001 para o curso de Medicina, o modelo de ensino possui seis anos de duração divididos em três ciclos de dois anos cada: ciclo básico, ciclo clínico e internato. No ciclo básico, são ministradas disciplinas bases para o curso, como por exemplo Anatomia, Fisiologia e Patologia. No ciclo clínico, o aluno se adentra mais na realidade médica, com disciplinas sobre as especialidades médicas. Já no internato o aluno passa a vivenciar atendimentos e procedimentos médicos com mais autonomia (BRASIL, 2001).

Essas diretrizes passaram por reformulações, e em 2014 um novo documento é publicado, estabelecendo que o perfil esperado do egresso em Medicina seja de um profissional com formação geral, humanista, crítica, reflexiva e ética, com capacidade para atuar nos diferentes níveis de atenção à saúde, com ações de promoção, prevenção, recuperação e reabilitação da saúde (BRASIL, 2014).

O estudante de Medicina, desde a sua preparação para o vestibular, é submetido a um processo delicado de cobrança e pressão psicológica (CARDOSO FILHO et al., 2015) e mesmo com sua aprovação e ingresso no curso, as dificuldades e cobranças se perpetuam ao longo da graduação, o que pode gerar um quadro de insegurança, cansaço e tristeza (FEODRIPPE; BRANDÃO; VELENTE, 2013). Os estudantes de Medicina são conduzidos a buscarem o máximo de sua capacidade intelectual objetivando uma formação de excelência, de forma que viver nesse padrão pode tornar aspectos inerentes a uma boa qualidade de vida esquecidos no cotidiano desses acadêmicos. Os discentes na tentativa de responder as exigências da família, dos professores e da sociedade, comumente deixam de lado os momentos de singularidade e subjetividade, pois podem sentirem-se culpados e angustiados com o simples fato de ter esses componentes no seu dia a dia (MAIA et al., 2011).

A partir daí a Medicina passa a ser vista como uma frustração, devido ao grande acúmulo de disciplinas e conteúdos, da necessidade de um amadurecimento precoce, da carga de responsabilidade aplicada, falta de preparo psicológico, resultando em privações dos mais 
diversos níveis, a partir de uma total dedicação aos estudos e falta de tempo para atividades de lazer e descanso - como a prática de atividades físicas, bom aproveitamento do sono e interação com amigos e familiares (FIOROTTI; ROSSONI; MIRANDA, 2009) -, podendo vir a alterar a condição psicológica do aluno e seu futuro profissional (HARADA et al., 2013).

Organismos como a Organização Mundial da Saúde (OMS), Organização PanAmericana da Saúde (OPAS) e Associação Brasileira de Escolas de Medicina (ABEM) têm manifestado, nas últimas décadas, uma grande preocupação com o ensino médico especialmente com relação à saúde e bem-estar discente (FERREIRA et al. 2000). Faz-se necessário refletir sobre o ensino atual, em busca de modelos educacionais mais adequados à formação médica e à melhor qualidade de vida e, portanto, ter um maior conhecimento do perfil do aluno de Medicina traz contribuições na proposição de soluções às preocupações instaladas pelo ensino médico (FIOROTTI; ROSSONI; MIRANDA, 2009).

Neste contexto, o objetivo deste estudo foi traçar o perfil do estudante dos dois primeiros anos do curso de Medicina de uma instituição privada de ensino superior da Zona da Mata mineira, através de aspectos como: perfil socioeconômico e acadêmico, qualidade de vida e lazer, percepções sobre o curso e expectativas profissionais futuras.

\section{MÉTODOS}

Estudo transversal, descritivo, de abordagem quantitativa, cuja amostra foi constituída pelos alunos regularmente matriculados nos dois primeiros anos do curso de Medicina de uma instituição privada de ensino superior da Zona da Mata mineira, no segundo semestre de 2017. Como instrumento de coleta de dados, foi aplicado um questionário auto analisável e anônimo, composto por 37 perguntas objetivas e duas discursivas, adaptado de Cardoso Filho e outros (2015) e Fiorotti e outros (2009). O questionário versava sobre dados socioeconômicos, informações sobre histórico escolar, condições relacionadas a vida acadêmica, qualidade de vida e lazer, percepções sobre o curso e perspectivas com relação ao futuro profissional.

Os dados obtidos não possuíram qualquer identificação dos participantes, mantendo sempre o anonimato, o sigilo e a confidência e, desse modo, seguindo as diretrizes e os critérios instituídos na Resolução 466/12 do Conselho Nacional de Saúde (CNS). Durante a aplicação dos questionários, os entrevistados foram esclarecidos sobre os objetivos da pesquisa e só participaram respondendo ao questionário aqueles que declararam, por escrito, a aceitação 
mediante a assinatura do Termo de Consentimento Livre e Esclarecido - TCLE. O desenvolvimento e aplicação dos questionários ocorreram após submissão e aprovação do projeto ao Comitê de Ética em Pesquisa institucional sob o parecer $\mathrm{N}^{\circ} 2.084 .442$.

Após a coleta dos dados, foi realizada a análise descritiva dos dados. O armazenamento, análise estatística, e apresentação dos resultados foram realizadas com auxílio do software Microsoft @ Excel 2010. Para análise interpretativa, os resultados foram organizados em variáveis categóricas e expressos em frequências absolutas e relativas.

\section{RESULTADOS}

Dos 112 alunos da população amostral considerada, obteve-se retorno de 90 questionários respondidos (80,35\% da amostra selecionada), representados por 23 alunos do $1^{\circ}$ período (25,55\%), 25 alunos do $2^{\circ}$ período $(27,77 \%), 22$ alunos do $3^{\circ}$ período $(24,44 \%)$ e 20 alunos do $4^{\circ}$ período $(22,22 \%)$.

A Tabela 1 apresenta dados acerca do perfil socioeconômico dos discentes dos dois primeiros anos do curso de Medicina da instituição investigada. Foi observada uma prevalência de discentes do gênero feminino (64,77\%), com idade média de 22 anos (23,33\%), etnia branca $(61,79 \%)$, solteiros $(96,51 \%)$, que não possuem filhos $(98,79 \%)$, naturais de Minas Gerais (78,66\%), que moram com amigos (58,13\%), que tem pais com Ensino Médio completo $(26,43 \%)$ e mães com Ensino Superior completo (34,48\%). A maioria dos discentes disse ter renda mensal familiar superior a sete salários mínimos $(62,35 \%)$, com quatro pessoas dependentes dessa renda (48,80\%). Ademais, a maioria dos discentes investigados informaram ter contato frequente com a família $(31,25 \%)$, na qual incluem-se médicos como seus familiares $(56,17 \%)$.

Tabela 1: Perfil socioeconômico dos acadêmicos dos dois primeiros anos do curso de medicina da instituição investigada.

\begin{tabular}{lcc}
\hline VARIÁVEL & {$[\mathbf{N}]$} & {$[\%]$} \\
\hline Gênero & & \\
Masculino & 31 & 35,22 \\
Feminino & 57 & 64,77 \\
Idade & & \\
$\mathbf{2 0}$ & 18 & 20,00 \\
$\mathbf{2 1}$ & 15 & 16,88 \\
$\mathbf{2 2}$ & 21 & 23,33 \\
$\mathbf{2 2 3}$ & 16 & 17,77 \\
Etnia & & 61,79
\end{tabular}


Indígena

Estado civil

Solteiro

Casado

Divorciado

Outro

Possui filhos

1 filho

2 filhos

3 filhos ou mais

Não possui filhos

Naturalidade

Minas Gerais

Rio de Janeiro

Espírito Santo

12,00

8,00

Outro

Com quem mora

Pais

Outros familiares

58,13

migos

31,39

Outros

Grau de escolaridade do pai

Ensino Fundamental incompleto 11

12,64

Ensino Fundamental completo

17,24

Ensino Médio incompleto

8,04

Ensino Médio completo

Ensino Superior completo

21,83

Pós-graduação/mestrado/doutorado

13,79

Grau de escolaridade da mãe

Ensino Fundamental incompleto

Ensino Fundamental completo

2,29

2,29

Ensino Médio incompleto

20,68

34,48

Ensino Superior completo

32,18

Renda mensal do grupo familiar

Até 1 salário mínimo

De 2 a 4 salários mínimos

8,23

De 5 a 7 salários mínimos

29,41

16,47

De 7 a 9 salários mínimos

45,88

Número de pessoas que dependem da renda

1 pessoa

2 pessoas

10,71

3 pessoas

30,95

4 pessoas

48,80

Mais de 4 pessoas

9,52

Frequência de contato com a família

1 vez por mês

2 vezes por mês

17,50

23,75

Frequentemente

31,25

Esporadicamente

25,88

Familiar médico

Possui

56,17 
Fonte: Dados da pesquisa (2018).

Com relação à história escolar e acadêmica (Tabela 2), foi observada a prevalência de discentes que cursaram o Ensino Fundamental (69,31\%) e Ensino Médio (79,31\%) todo ou em sua maior parte em escolas particulares, que tentaram o vestibular por três ou mais vezes (70,93\%), tentaram o Exame Nacional do Ensino Médio (ENEM) por três vezes $(37,77 \%)$; se prepararam após Ensino Médio por até dois anos (39,32\%), que se decidiram pela Medicina entre os 17 e 19 anos (35,95\%), que não possuem atividade acadêmica remunerada (98,79\%), com domínio em língua inglesa $(76,40 \%)$ e que não cursaram outro curso superior anteriormente $(87,50 \%)$.

Tabela 2: História escolar e acadêmica.

\begin{tabular}{|c|c|c|}
\hline VARIÁVEL & {$[\mathbf{N}]$} & {$[\%]$} \\
\hline \multicolumn{3}{|l|}{ Colégio onde cursou o Ensino Fundamental } \\
\hline Todo ou a maior parte em escola pública & 26 & 29,54 \\
\hline Todo ou a maior parte em escola particular & 61 & 69,31 \\
\hline Outro & 1 & 1,13 \\
\hline \multicolumn{3}{|l|}{ Colégio onde cursou o Ensino Médio } \\
\hline Todo ou a maior parte em escola pública & 18 & 20,68 \\
\hline Todo ou a maior parte em escola particular & 69 & 79,31 \\
\hline Outro & - & - \\
\hline \multicolumn{3}{|c|}{ Número de vezes que tentou vestibular (incluindo o vestibular da instituição investigada) } \\
\hline $1 \mathrm{vez}$ & 14 & 16,27 \\
\hline 2 vezes & 11 & 12,79 \\
\hline 3 vezes ou mais & 61 & 70,93 \\
\hline \multicolumn{3}{|l|}{ Número de vezes que tentou o ENEM } \\
\hline 1 vez & 7 & 7,77 \\
\hline 2 vezes & 26 & 28,88 \\
\hline 3 vezes & 34 & 37,77 \\
\hline 4 vezes ou mais & 23 & 25,55 \\
\hline \multicolumn{3}{|l|}{ Anos de preparo após o Ensino Médio } \\
\hline Aprovação após conclusão do Ensino Médio & 4 & 4,49 \\
\hline Até 1 ano & 28 & 31,46 \\
\hline Até 2 anos & 35 & 39,32 \\
\hline 3 anos ou mais & 22 & 24,71 \\
\hline \multicolumn{3}{|l|}{ Momento em que decidiu pela Medicina } \\
\hline Na infância & 26 & 29,21 \\
\hline 14-16 anos & 26 & 29,21 \\
\hline 17-19 anos & 32 & 35,95 \\
\hline 20-22 anos & 3 & 3,37 \\
\hline 23-25 anos & 1 & 1,12 \\
\hline 26 anos ou mais & 1 & 1,12 \\
\hline \multicolumn{3}{|l|}{ Exerce atividade acadêmica remunerada } \\
\hline Monitoria & 1 & 1,20 \\
\hline Extensão & - & - \\
\hline Pesquisa & - & - \\
\hline Nenhuma & 82 & 98,79 \\
\hline \multicolumn{3}{|l|}{ SAÚDE DINÂMICA - Revista Científica Eletrônica } \\
\hline 1a Edição 2019 | Ano I, no 1 | ISSN-2675-133X & & \\
\hline
\end{tabular}


Domínio em línguas estrangeiras*

Inglês

Espanhol

68

Francês

47

76,40

4

Outra

Já cursou outra graduação

Não

* Nesta pergunta foi permitida a escolha de mais de uma alternativa, logo, as porcentagens apresentadas dizem respeito ao total de alunos respondentes por alternativa.

Fonte: Dados da pesquisa (2018).

A Tabela 3 destaca informações sobre qualidade de vida, onde observou-se um predomínio de discentes que praticam atividade física regular ou eventualmente de $(72,21 \%)$, que fazem uso de bebida alcoólica (60\%), que consideraram a carga excessiva de atividades acadêmicas como o fator estressante que mais interfere em sua qualidade de vida $(75,55 \%)$ e que relataram a ansiedade como a dificuldade que mais interfere no desempenho acadêmico $(81,11 \%)$. Grande parte dos entrevistados $(53,48 \%)$ nunca se submeteram à atendimento com psicólogo ou psiquiatra durante o curso, e a maioria $(63,63 \%)$, procurou apoio psicopedagógico clínico ou institucional apenas uma vez durante o curso.

Tabela 3: Informações sobre qualidade de vida.

\begin{tabular}{|c|c|c|}
\hline VARIÁVEL & {$[\mathbf{N}]$} & {$[\%]$} \\
\hline \multicolumn{3}{|l|}{ Prática de atividades físicas } \\
\hline Sim & 44 & 48,88 \\
\hline Não & 25 & 27,77 \\
\hline Às vezes & 21 & 23,33 \\
\hline \multicolumn{3}{|l|}{ Faz uso de remédios/substâncias* } \\
\hline Bebida alcoólica & 54 & 60,00 \\
\hline Cigarro & 15 & 16,66 \\
\hline Psicoestimulantes & 12 & 13,33 \\
\hline Remédios para dormir & 8 & 8,88 \\
\hline Não usa nenhuma dessas substâncias & 21 & 23,33 \\
\hline Outros & 3 & 3,33 \\
\hline \multicolumn{3}{|c|}{ Fator estressante que mais interfere na vida acadêmica* } \\
\hline Adaptação a novas situações & 16 & 17,77 \\
\hline Carga excessiva de atividades acadêmicas & 68 & 75,55 \\
\hline Distância da família & 28 & 31,11 \\
\hline Outro & - & - \\
\hline \multicolumn{3}{|c|}{ Dificuldade que mais interfere no desempenho acadêmico } \\
\hline Ansiedade & 73 & 81,11 \\
\hline Insônia & 11 & 12,22 \\
\hline Transtornos Cognitivos & 8 & 8,88 \\
\hline Outro & 10 & 1,11 \\
\hline \multicolumn{3}{|c|}{ Atendimento psicológico ou psiquiátrico durante o curso } \\
\hline Nunca se submeteu & 46 & 53,48 \\
\hline Atendimento psiquiátrico & 14 & 16,27 \\
\hline Atendimento psicológico & 26 & 30,23 \\
\hline
\end{tabular}


Apoio psicopedagógico clínico ou institucional

Procurou apenas 1 vez

Procura apenas quando apresenta alguma dificuldade em

* Nestas perguntas foi permitida a escolha de mais de uma alternativa, logo, as porcentagens apresentadas dizem respeito ao total de alunos respondentes por alternativa.

Fonte: Dados da pesquisa (2018).

As informações sobre lazer e cultura são apresentadas na Tabela 4. A partir de sua análise, observou-se a prevalência de discentes com menos de quatro horas livres diárias para realização de atividades de lazer $(78,88 \%)$, que usam computador/televisão/internet $(58,88 \%)$, descansam $(51,11 \%)$ ou saem com amigos ou namorado(a) $(51,11 \%)$ nas horas livres, e cuja principal fonte de informação sobre as atualidades é a internet (97,75\%).

Tabela 4: Informações de lazer e cultura.

\begin{tabular}{lcc}
\hline \multicolumn{1}{c}{ VARIÁVEL } & {$[\mathbf{N ]}$} & {$[\%]$} \\
\hline Horas diárias livres & & 10,00 \\
Nenhuma & 9 & 44,44 \\
Até 2 & 40 & 34,44 \\
De 2 4 & 31 & 11,11 \\
Mais de 4 & 10 & 51,11 \\
O que costuma fazer nas horas livres* & & 6,66 \\
Sair com amigos / namorado (a) & 46 & 58,88 \\
Atividade cultural & 6 & 41,11 \\
Usar computador / internet / televisão & 53 & 25,55 \\
Praticar esportes ou academia & 37 & 51,11 \\
Ir à igreja & 23 & - \\
Descansar & 46 & 97,75 \\
Outros & - & 11,23 \\
Principais fontes de informação* & & 5,61 \\
Internet & 87 & 2,24 \\
Televisão & 10 & - \\
Jornal & 5 & 2 \\
Revista & & \\
Outro & - & \\
\hline
\end{tabular}

* Nestas perguntas era permita a escolha de mais de uma alternativa, logo, as porcentagens apresentadas dizem respeito ao total de alunos respondentes por alternativa.

Fonte: Dados da pesquisa (2018).

Com relação às informações acerca do curso e as expectativas profissionais (Tabela 5), foi observado que a possibilidade de realização profissional foi a principal motivação apontada como escolha pela Medicina $(62,22 \%)$ e que, a maioria dos discentes entrevistados considerou seu rendimento escolar bom $(76,13 \%)$. A maioria dos respondentes $(71,91 \%)$ nunca pensou em abandonar o curso e considera o estudo individual a principal fonte de contribuição para o 
aprendizado (76,66\%). Dos entrevistados, grande parte considerou ter muito interesse nos estudos $(58,88 \%)$, têm pretensão de fazer residência médica após a formatura $(62,22 \%)$ e acreditam que irão se realizar profissional e financeiramente $(77,27 \%)$.

Tabela 5: Informações acerca do curso e expectativa profissional.

\begin{tabular}{|c|c|c|}
\hline VARIÁVEL & {$[\mathbf{N}]$} & {$[\%]$} \\
\hline \multicolumn{3}{|l|}{ Principais motivações que levaram à escolha do curso de Medicina* } \\
\hline Aptidões pessoais e vocacionais & 47 & 52,22 \\
\hline Possibilidade de realização profissional & 56 & 62,22 \\
\hline Possibilidade de contribuir com a sociedade & 48 & 53,33 \\
\hline Desejo em ajudar e servir pessoas ou trabalhar com pessoas & 53 & 58,88 \\
\hline Empregabilidade ou diversidade ou áreas de atuação & 33 & 36,66 \\
\hline Bons salários / status social & 39 & 43,33 \\
\hline Identificação com o curso & 48 & 53,33 \\
\hline Curiosidade científica & 12 & 13,33 \\
\hline Gosto pela área biológica & 29 & 32,22 \\
\hline Influência de terceiros & 12 & 13,33 \\
\hline Fantasia ou sonho desde a infância & 19 & 21,11 \\
\hline Opção pessoal sem outras explicações & 8 & 8,88 \\
\hline \multicolumn{3}{|l|}{ Consideração do desempenho escolar } \\
\hline Ruim & - & - \\
\hline Regular & 15 & 17,04 \\
\hline Bom & 67 & 76,13 \\
\hline Excelente & 6 & 6,81 \\
\hline \multicolumn{3}{|l|}{ Pensamento em abandonar o curso } \\
\hline Nunca pensou & 64 & 71,91 \\
\hline Já pensou e ainda pensa & 7 & 7,86 \\
\hline Já pensou, mas não pensa mais & 18 & 20,22 \\
\hline \multicolumn{3}{|l|}{ Fontes que mais contribuem para o aprendizado* } \\
\hline Estudo individual & 69 & 76,66 \\
\hline Aulas expositivas & 35 & 38,88 \\
\hline Aulas práticas & 44 & 48,88 \\
\hline Estudo em grupo & 21 & 23,33 \\
\hline \multicolumn{3}{|l|}{ Interesse nos estudos } \\
\hline Muito interesse & 49 & 58,88 \\
\hline Interesse moderado & 30 & 35,71 \\
\hline Pouco interesse & 5 & 5,95 \\
\hline Não tem interesse & - & - \\
\hline \multicolumn{3}{|l|}{ O que pretende fazer quando se formar* } \\
\hline Se tornar um médico especialista/subespecialista & 55 & 61,11 \\
\hline Ser um médico generalista & 8 & 8,88 \\
\hline Trabalhar exclusivamente para o SUS & 3 & 3,33 \\
\hline Compatibilizar saúde pública e privada & 37 & 41,11 \\
\hline Trabalhar conforme as demandas do mercado & 13 & 14,44 \\
\hline Conciliar trabalho e qualidade de vida & 47 & 52,22 \\
\hline Buscar competência profissional & 44 & 48,88 \\
\hline Fazer residência médica & 56 & 62,22 \\
\hline Muito cedo para opinar & 4 & 4,44 \\
\hline Outra alternativa & - & - \\
\hline \multicolumn{3}{|l|}{ Perspectivas financeiras e de trabalho } \\
\hline Acha que não vai se realizar profissionalmente, nem financeiramente & - & - \\
\hline \multirow{2}{*}{$\begin{array}{l}\text { Acha que não vai se realizar profissionalmente, mas a perspectiva } \\
\text { financeira é boa }\end{array}$} & 3 & 3,40 \\
\hline & & \\
\hline \multicolumn{3}{|l|}{ SAÚDE DINÂMICA - Revista Científica Eletrônica } \\
\hline 1a Edição 2019 | Ano I, no 1 | ISSN-2675-133X & & \\
\hline
\end{tabular}


* Nestas perguntas foi permitida a escolha de mais de uma alternativa, logo, as porcentagens apresentadas dizem respeito ao total de alunos respondentes por alternativa.

Fonte: Dados da pesquisa (2018).

\section{DISCUSSÃO}

Os resultados deste estudo descreveram o perfil dos estudantes de Medicina de uma instituição privada de ensino situada na Zona da Mata Mineira. Apesar da pesquisa ter traçado o perfil dos discentes de Medicina de uma única instituição e limitar-se a definir as características de discentes matriculados apenas nos dois primeiros anos do curso, traz contribuições ao debate sobre a educação médica, uma vez que as expectativas iniciais dos discentes trazem contribuições importantes sobre a investigação do ensino médico. Pela análise dos resultados, é possível perceber uma prevalência maior de discentes do sexo feminino (64,77\%), corroborando com o padrão encontrado nos estudos de Fiorotti e outros (2009); Ferreira e outros (2000); Lima e outros (2006) e, contrastando com o resultado obtido por Ferreira e outros (2000), realizado na Universidade Federal de Minas Gerais (UFMG), instituição pública mineira, no qual houve predomínio de discentes do sexo masculino $(53,90 \%)$.

A maior prevalência de estudantes com 22 anos em nosso estudo (23,33\%) se mostrou menor em relação à média nacional de 24 anos de idade (73,70\%), relatada pelo Fórum Nacional de Pró-Reitores de Assuntos Comunitários e Estudantis de 2011, bem como a média de até 26 anos obtida entre os estudantes da Universidade Estadual de Londrina encontrada por Finatti e outros (2007) e pela média de 23 a 24 anos de idade (27,8\%) encontrada entre os estudantes de Medicina da Universidade Estadual do Estado do Rio Grande do Norte (UERN), no estudo conduzido por Cardoso Filho e outros (2015). Tal resultado, pode ser explicado pelo fato de termos considerado apenas estudantes do primeiro e segundo anos do curso de medicina e os outros estudos considerarem todos os estudantes do curso. Entretanto, nossos resultados quanto a etnia e estado civil se assemelharam aos resultados encontrados por Fiorotti e outros (2009), que encontraram predomínio de discentes da etnia branca $(68,5 \%)$ e de solteiros $(98,7 \%)$ entre os estudantes de Medicina da Universidade Federal do Espírito Santo (UFES), e 
por Cardoso Filho e outros (2015), que indicaram a prevalência de 48,6\% de discentes da etnia branca e 90,3\% de solteiros na UFMG. No quesito não possuir filhos, os dados do nosso estudo (98,79\%) acompanharam a realidade nacional (90,2\% de estudantes sem filhos) (FÓRUM NACIONAL, 2011), em conjunto com os estudos da UFMG e UFES, nos quais a maioria dos estudantes de Medicina (91,7\% e 98,3\%) também não possuíam filhos (FERREIRA et al., 2000, FIOROTTI; ROSSONI; MIRANDA, 2009).

Grande parte dos estudantes analisados em nosso estudo é natural do estado onde estudam $(78,66 \%)$, o que também foi visto em outras instituições nacionais (FÓRUM NACIONAL, 2011, FINATTI; ALVES; SILVEIRA, 2007). Uma possível explicação para este achado pode ser atribuída à vontade dos estudantes de estarem mais próximos da família, resultando na escolha de universidades no mesmo estado de origem para o vestibular. Em relação ao grau de escolaridade familiar, observamos maior prevalência de alunos com mães cujo grau de escolaridade é o Ensino Superior completo (34,48\%), e cujos pais possuem Ensino Médio completo $(26,43 \%)$, contrastando com os resultados obtidos entre os estudantes de Medicina da UFMG e UFES, que apresentaram maior prevalência de discentes com mães e pais com Ensino Superior completo (FERREIRA et al., 2000, FIOROTTI; ROSSONI; MIRANDA, 2009).

A renda familiar para $62,35 \%$ dos acadêmicos analisados se demonstrou superior a sete salários mínimos, o que reforça a comprovação de um nível socioeconômico maior desse grupo de estudantes em relação à comunidade acadêmica em geral. Segundo Fiorotti e outros (2009), o curso de Medicina, por ser um curso com maior carga horária e de custo elevado, possui alunos, em sua maioria, sem tempo para estágios remunerados e que são sustentados pelos pais, o que seleciona estudantes em melhor situação socioeconômica. Neste viés, observou-se em nosso estudo que, em relação ao número de pessoas dependentes da renda mensal, há o predomínio $(48,8 \%)$ de discentes em que quatro é o número de pessoas dependentes da renda familiar mensal, o que corrobora com o estudo de Cardoso Filho e outros (2015), no qual 37,5\% os alunos da UERN também responderam que quatro são os dependentes da renda mensal familiar.

O contato com a família neste estudo se mostrou frequente $(31,25 \%)$. Isso se deve, provavelmente, ao fato da maioria dos estudantes ser natural do interior do estado de Minas Gerais, o que deve ajudá-los a enfrentar melhor as dificuldades encontradas nos estudos e na grande carga horária do curso de Medicina. Adicionalmente, a presença de familiares médicos 
também foi frequente $(56,17 \%)$, assim como o obtido nos resultados $(65 \%)$ do estudo de Teixeira e outros, (2008) realizado entre estudantes do curso de Medicina da PUC-RS.

A maioria dos discentes da instituição estudou durante todo tempo ou em maior parte dele em escolas privadas no Ensino Fundamental (69,31\%) e Médio (79,31\%), corroborando com outros estudos nacionais (REZENDE et al., 2008, FIOROTTI; ROSSONI; MIRANDA, 2009). Com relação ao número de vestibulares prestados, a maioria tentou três mais provas de vestibular (70,93\%), corroborando com Cardoso Filho e outros (2015), no qual 59,7\% dos discentes prestaram três ou mais vestibulares, e divergindo dos resultados obtidos por Fiorotti e outros (2009), no qual observou-se predominância de alunos aprovados no segundo vestibular (34,9\%). Com relação ao ENEM, a maioria realizou o exame por três vezes $(37,77 \%)$ e, com relação ao tempo de aprovação no curso de Medicina após conclusão do Ensino Médio, a maioria $(39,32 \%)$ levou até dois anos. O não ingresso imediato à graduação pode ser atribuído à grande concorrência do ENEM e dos vestibulares de Medicina, uma vez que este curso é um dos mais desejados no Brasil.

Assim como no estudo de Cardoso Filho e outros (2015) realizado na UERN, na instituição em questão, a maior parte dos estudantes participantes da pesquisa não exerce atividade acadêmica remunerada (98,79\%). Essa prevalência muitas vezes não se dá pela falta de interesse dos estudantes, mas sim pelo número restrito de vagas, pela exigência de bons coeficientes de rendimento acadêmico e pela falta de tempo de dedicação para participação nessas atividades.

A maior parte dos acadêmicos investigados é de praticantes regulares ou eventuais de atividades físicas $(72,21 \%)$, ao contrário do que foi encontrado por Cardoso Filho e outros (2015) e por Maia e outros (2012), que encontraram estudantes de Medicina não praticantes de atividades físicas $(48,6 \%)$ ou sedentários $(51,2 \%)$ em sua maioria. Em contrapartida, o consumo de bebidas alcoólicas foi significativo (60\%), assim como foi descrito por Ramos-Dias e outros (2010) em seu estudo com alunos do curso de Medicina de Sorocaba da PUC-SP e por Cardoso Filho e outros (2015).

Entre os fatores estressantes que mais interferem na vida acadêmica, a carga excessiva de atividades $(75,55 \%)$ foi a mais indicada entre os discentes deste estudo, a qual também foi relatada em diversos estudos nacionais realizados com estudantes de escolas médicas de instituições públicas e privadas de ensino (FÓRUM NACIONAL, 2011, FIOROTTI; ROSSONI; MIRANDA, 2009, LIMA; DOMINGUES; CERQUEIRA, 2006, FEODRIPPE; 
BRANDÃO; VALENTE, 2013, FURTADO; FALCONE; CLARK, 2003). Com relação à dificuldade que mais interfere no desempenho acadêmico, a ansiedade foi a principal apontada $(81,11 \%)$, corroborando com os resultados obtidos entre os estudantes de medicina investigados por Ramos-Dias e outros (2010) e Cardoso Filho e outros (2015).

Muitos dos alunos pertencentes ao grupo abordado não se submeteram a atendimento psiquiátrico ou psicológico durante o curso $(53,48 \%)$. A porcentagem de alunos que já procuraram atendimento psiquiátrico foi de $16,27 \%$, o que é alto em relação ao nível nacional (9\%), que vai de encontro com Cardoso Filho e outros (2015). Nessa mesma vertente, 30,23\% deles já buscaram atendimento psicológico, enquanto que no país 29\% tiveram essa atitude. Com relação ao apoio psicopedagógico em clínicas ou na própria instituição, os dados demonstraram que a maioria $(63,63 \%)$ procurou esse atendimento apenas uma vez durante o curso, contrastando com os dados nacionais de 10\% (FÓRUM NACIONAL, 2011), o que coloca a questão do apoio psicológico como um tema de relevância no tocante ao bem estar dos estudantes de Medicina, visto a vulnerabilidade psicológica apresentada por estes acadêmicos nas diversas instituições nacionais, com resultados de perdas à saúde mental.

Em relação às informações de lazer e cultura, o número de horas livres diárias para realização de atividades de lazer da maioria dos estudantes $(88,88 \%)$ é menor que quatro horas, momento em que fazem o uso do computador, acessam a internet ou assistem programas de televisão $(58,88 \%)$, descansam $(51,11 \%)$ ou saem com amigos ou namorado(a) $(51,11 \%)$. Nossos resultados corroboram em parte com os resultados obtidos por Fiorotti e outros (2009), que apresenta que a maioria dos estudantes abordados $(90,4 \%)$ possui apenas algumas horas livres nos finais de semana para lazer.

Pesquisar sobre o motivo que leva os discentes à escolha do curso é difícil, e as motivações envolvidas podem ser conscientes e inconscientes (RIBEIRO et al., 2011). Em nosso estudo, o principal motivo apontado foi a possibilidade de realização profissional com $62,22 \%$. Ferreira e outros (2000) encontraram a identificação com a profissão, Fiorotti e outros (2009) encontraram a aptidão pessoal e vocacional e Ribeiro e outros (2011), avaliando estudantes do primeiro ciclo do curso profissional da Faculdade de Medicina da UFMG, encontraram e a empregabilidade e a possibilidade de bons salários como os motivos mais frequentes para a escolha da profissão.

Após a conclusão do curso, a maioria dos discentes deste estudo relatou a vontade de fazer residência médica $(62,22 \%)$, e 77,27\% deles relataram acreditar na realização profissional 
e financeira. Esse pensamento corrobora Ferreira e outros (2000), já que a maioria do grupo estudado tem a residência médica e um bom salário como principais objetivos após se formarem, e preferiram outras formas de trabalho à prestação de serviços ao Sistema Único de Saúde (SUS).

\section{CONCLUSÃO}

Esta pesquisa, apesar de ter traçado o perfil dos discentes de Medicina de uma única instituição e limitar-se a definir as características de discentes matriculados apenas nos dois primeiros anos do curso, traz contribuições ao debate sobre a educação médica, já que as propostas de transformação de ensino devem dar atenção à bagagem que o discente é portador, às suas perspectivas iniciais e às suas aspirações futuras.

O perfil dos acadêmicos de Medicina da instituição de Ensino Superior investigada indica que estes estudantes são, em sua maioria, jovens adultos do sexo feminino, solteiros, sem filhos, naturais do estado onde a instituição se localiza e com renda mensal familiar superior a sete salários mínimos. Além disso, são oriundos de escolas particulares, que prestaram pelo menos três vestibulares, com familiares médicos e que não exercem qualquer atividade acadêmica remunerada. Ademais, a maioria relata ingerir bebidas alcoólicas e ter poucas horas diárias para o lazer.

Embora considerem a carga de atividades acadêmicas excessiva e a ansiedade como o principal fator de interferência no desempenho acadêmico, a maioria nunca se submeteu a atendimento psicológico ou psiquiátrico e buscou por apoio psicopedagógico por apenas uma vez durante o curso. A possibilidade de realização profissional foi a principal motivação para a escolha pela Medicina entre os estudantes investigados, que em sua maioria avaliaram o seu rendimento escolar como bom, têm pretensão de fazer residência médica após a formatura e acreditam na realização profissional e financeira.

Diante dos aspectos abordados neste estudo, foi possível perceber semelhanças entre os nossos resultados e os resultados de outras pesquisas, principalmente no em relação ao elevado nível sócio econômico destes discentes, suas queixas de excessiva carga de atividades e a pretensão de realização de residência médica após a formatura. Dessa forma, fica claro que estudos mais apurados sobre o tema são necessários para que haja um entendimento global da 
situação a qual o estudante de Medicina se encontra nas diversas instituições nacionais, afim de que medidas possam ser adotadas no âmbito das escolas médicas.

\section{REFERÊNCIAS}

BRASIL. Ministério da Educação. Conselho Nacional de Educação. Câmara de Educação Superior. Resolução CNE/CES n ${ }^{\circ} 4$ de 7 de novembro de 2001. Institui diretrizes curriculares nacionais do curso de graduação em Medicina. Diário Oficial da União. Brasília, 9 nov. 2001; Seção 1, p.38.

BRASIL. Ministério da Saúde. Conselho Nacional de Saúde. Comissão Nacional de Ética em Pesquisa. Resolução CNS/Conep n466, de 12 de dezembro de 2012. Diário Oficial da União, Brasília, 13 jun. 2013; Seção 1, p. 59.

BRASIL. Ministério da Educação. Conselho Nacional de Educação. Câmara de Educação Superior. Resolução no 3, de 20 de junho de 2014. Institui diretrizes curriculares nacionais do curso de graduação em Medicina e dá outras providências. Diário Oficial da União, Brasília, 23 jun. 2014; Seção 1, p. 8-11.

CARDOSO FILHO, F. A., MAGALHÃES, J. F.; SILVA, Q. M. L.; PEREIRA, I. S. S. D. Perfil do estudante de medicina da universidade do estado do Rio Grande do Norte (UERN), 2013. Revista Brasileira de Educação Médica, Brasília, v. 39, n. 1, p. 32-40, 2015.

FACULDADE DE MEDICINA - UFMG. Perfil dos alunos de Medicina muda nos últimos 10 anos. Disponível em: < https://site.medicina.ufmg.br/inicial/perfil-dos-alunos-de-medicinamuda-nos-ultimos-10-anos\%EF\%BB\%BF/>. Jan. 2019. Acesso em: 15 de abr. 2019.

FEODRIPPE, A. L. O.; BRANDÃO, M. C. F.; VALENTE, T. C. O. Qualidade de vida dos estudantes de medicina: uma revisão. Revista Brasileira de Educação Médica, Brasília, v. 37 , n. 3, p. 418-428, 2013.

FERREIRA, R. A.; PERRET FILHO, L. A.; GOULART, E. M. A.; VALADÃO, M. M. A. O estudante de medicina da Universidade Federal de Minas Gerais: perfil e tendências. Revista da Associação Médica Brasileira, São Paulo, v. 46, n. 3, p. 224-231, 2000.

FINATTI, B.E.; ALVES, J.M.; SILVEIRA, R. J. Perfil socioeconômico e cultural dos estudantes da Universidade Estadual de Londrina: indicadores para implantação de uma política de assistência estudantil. Libertas, Juiz de Fora, v. 7, n. 2, p. 246-264, 2007. 
FIOROTTI, K. P.; ROSSONI, R. R.; MIRANDA, A. E. Perfil do estudante de medicina da Universidade Federal do Espírito Santo, 2007. Revista Brasileira de Educação Médica, Brasília, v. 34, n. 3, p. 355-362, 2009.

FÓRUM NACIONAL DE PRÓ-REITORES DE ASSUNTOS COMUNITÁRIOS E ESTUDANTIS. Perfil socioeconômico e cultural dos estudantes de graduação das universidades federais brasileiras. Brasília, jul, 2011. Disponível em: $<$ http://www.fonaprace.andifes.org.br/index.php?option=com_content\&view=article\&id=75:p erfil-socioeconomico-e-cultural-dos-estudantes-de-graduacao-das-universidades-federaisbrasileiras\&catid=35: nacional\&Itemid=58>. Acesso em 20 ago. 2017.

FURTADO, E. S.; FALCONE, E. M. O.; CLARK, C. Avaliação do estresse e das habilidades sociais na experiência acadêmica de estudantes de Medicina de uma universidade do Rio de Janeiro. Interação em Psicologia, Rio de Janeiro, v. 7, n. 2, p. 43-51, 2003.

HARADA, B.A.; FAXINA, C. F.; CAPELETTO, C. M.; SIMÕES, J. C. Perfil psicológico do estudante de Medicina. Revista do Médico Residente, Curitiba, v. 15, n. 2, p. 93-101, abr./jun. 2013.

IGNARRA, R. M. Medicina: representações de estudantes sobre a profissão. $208 \mathrm{f}$. Tese (Doutorado). Faculdade de Saúde Pública, Universidade de São Paulo. São Paulo, 2002.

LIMA, M. C. P.; DOMINGUES, M. S.; CERQUEIRA, A. T. A. R. Prevalência e fatores de risco para transtornos mentais comuns entre estudantes de Medicina. Revista de Saúde Pública, São Paulo, v. 40, n. 6, p. 1.035-1.041, dez., 2006.

MAIA, D. A. C. M.; MACIEL, R. H. M. O.; VASCONSElOS, J. A.; FILHO, J. O. V. Acadêmicos de medicina: sua relação com o ócio e a prática de atividade física como combate à ansiedade e ao estresse. Cadernos ESP, Fortaleza, v. 5, n. 1, p. 62-73, jan./jun., 2011.

MAIA, D. A. C. M.; MACIEL, R. H. M. O.; VASCONSELOS, J. A.; FILHO, J. O. V. Síndrome de Burnout em estudantes de medicina: relação com a prática de atividade física. Cadernos ESP, Fortaleza, v. 6, n. 2, p. 50-59, jul./dez., 2012.

RAMOS-DIAS, J. C.; LIBARDI, M. C.; ZILLO, C. M.; IGARASHI, M. H.; SENGER, M. H. Qualidade de vida em cem alunos do curso de medicina de Sorocaba - PUC/SP. Revista Brasileira de Educação Médica, Brasília, v. 34, n. 1, p. 116-123, 2010. 
RIBEIRO, M. M. F.; LEAL, S. S.; DIAMANTINO, F. C.; BIANCHI, H. A. A Opção pela Medicina e os Planos em relação ao futuro profissional de estudantes de uma faculdade pública brasileira. Revista Brasileira de Educação Médica, Brasília, v. 35, n.3, p. 405-411, 2011.

REZENDE, C. H. A.; ABRÃO, C. B.; COELHO, E. P.; PASSOS, L. B. S. Prevalência de sintomas depressivos entre estudantes de Medicina da Universidade Federal de Uberlândia. Revista Brasileira de Educação Médica, Brasília, v. 32, n. 3, p. 315-323, 2008.

TEIXEIRA, L.; ANTONELlO, I. C. F.; LOPES, M. H. I.; CATALDO NETO, A. Perfil do acadêmico ingressante na Faculdade de Medicina da PUCRS. IX Salão de Iniciação Científica - PUCRS, 2008. 